\title{
Design Clamping Device of Milling Fixture Base on Contradiction Matrix
}

\author{
Chuiyuan Zeng ${ }^{a}$, Shaohui Su ${ }^{b}$ \\ School of Hangzhou Dianzi University, Hangzhou 310018, China \\ acyuan_zeng@126.com, bmesshhui@163.com
}

Keywords: innovation design, TRIZ, IFR, contradiction matrix.

\begin{abstract}
TRIZ is one of the most important tool for innovative design. But the theory that how to use the tools of TRIZ to solve problems isn't mature. So, this paper puts forward a method, which introduces how to use contradiction matrix to solve problems that we meet when we design products. Firstly, we should make sure ideal final result (IFR) of products and find the problems of the products by the IFR, then compare the problems with engineering parameters and be sure deteriorative engineering parameters of the products. Secondly, find technical contradictions of the products by proposing conventional methods which we can use to deal with the problem obviously. Thirdly, seek contradiction matrix table and find the inventive principles according to the technical contradictions. Finally, translate the inventive principles to specific design ideas. In the end, this paper use design of clamping device in milling fixture as an example.
\end{abstract}

\section{Introduction}

TRIZ is one of effective innovative thinking methods which is used to solve the products problems. Comparing with trial and error, brainstorming and other innovative thinking methods, TRIZ can provide ideas that are used to solve similar problems and which are more likely to solve problems of products. Contradiction matrix as one of the important tool of TRIZ in deal with problems of products [1], it can solve most of the problems we meet while designing the products.

When designers handle problems of product, they often meet such situation: while they puts forward conventional methods to improve the problems, it will generate other problems meanwhile. For such technology contradictions, designers often use the compromise methods rather than real methods to handle the problems completely [2]. The contradiction matrix can solve this situation well, and solve the problems completely.

Contradiction matrix [3] is a matrix, which compose by 39 engineering parameters and 40 invention principles [4]. Contradiction matrix is a $39 \times 39$ matrix, in the first column and first row of the contradiction matrix are 39 serial number that represent engineering parameters. The first column and first row represent improvement engineering parameters and deteriorative parameters respectively. The number in the contradiction matrix cell represent invention principle that can deal with technology contradictions. That means these invention principle in the cell can solve corresponding technology contradiction. The steps using contradiction matrix to solve technology contradictions existing in product are shown below and the process is shown in figure 1.

1) Find the problems existing in the product and translate the problems into corresponding engineering parameters.

2) Make sure deteriorative engineering parameters and improvement engineering parameters of technical contradictions.

3) Look up contradiction matrix table and find invention principles that can solve the technology contradictions.

4) Translate the invention principles into specific design schemes.

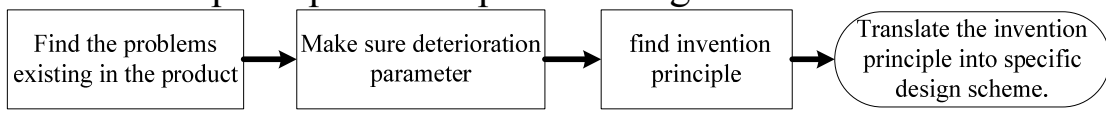

Fig. 1 Application process of contradiction matrix 


\section{Find the problems of product by IFR}

According to the steps given above, in order to use contradiction matrix in conceptual design, we should firstly find the problems existing in the product. This paper provide a method to find the problems existing in the product by using IFR of the system. According to the definition of the IFR of the system: System does not use additional resources, it can achieve desired function by itself, and at the same time it does not produce harmful functions [4]. Because IFR of the system does have harmful functions, and product conceptual design is to reduce the consumption of resource and the harmful functions of the product, that is meaning product innovation is the product looming in the IFR of the product. Designers can find out the problems existing in the product by comparing the existing product with IFR of the product. The steps how to use IFR to find out the problems existing in the product are shown below and the flow chart is show in figure 2.

1) According to existing products, make sure functions of the products.

2) Be sure IFR of the product.

3) Put forward assumptions and get the corresponding results: If we do not use the methods which is used in the products, the products won't generate the problems that we don't want to.

4) Contrast the products with IFR of the products, find out the problems existing in the products.

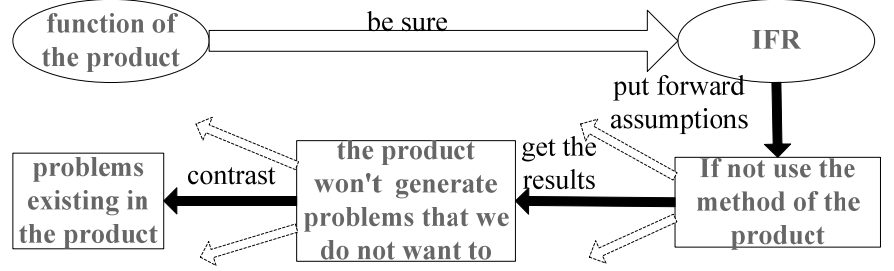

Fig. 2 The flow chart of using IFR to find problems of the product

Because the problems of the products that we get by IFR is specific, and the 39 engineering parameters are abstract. So, the problems of products cannot be applied directly. In order to apply contradiction matrix to solve the problems, we should convert them into corresponding engineering parameters. And 39 engineering parameters of the contradiction matrix can describe most of the technology contradictions in engineering field, so we can convert the problems that we get from IFR into corresponding engineering parameters. We can compare the problems with engineering parameters, and make sure what engineering parameters existing in the products.

\section{Be sure the invention principle of the technology contradictions}

To deal with the problems of the products, designers should firstly try to propose conventional method which can solve the problems directly. If the method can solve the problems and doesn't cause other parameters go bad, we can use this method in the product design, else we can't use this method in the product design, and the problems are one parameter of technology contradictions respectively. In this case, we should use contradiction matrix to deal with the problems.

Before we use contradiction matrix to deal with the problems existing in the products, we should find out both two parameters which compose technology contradiction. One of the parameters is that existing in the product, and we want to improve. The other is that when we improve the parameters the product will generate. Because it is difficult for we to make sure deteriorative parameters directly by the improvement parameters. So we can try to put forward to conventional method to solve the problem, and find what parameters will deteriorate, and this parameters will be the deteriorative parameters [5]. Then we can look up contradiction matrix table to find out the inventive principles to solve the technology contradictions. The steps of using the contradiction matrix to solve the technology contradiction and get preliminary design ideas are shown below and the flow chart is shown in figure 3.

1) Propose conventional methods to solve problems of the products.

2) If the method will cause other parameters go bad, we find out it and make sure the technology contradictions. 
3) Look up contradiction matrix table to find the inventive principles that can solve the technology contradictions.

4) Finally, translate the invention principles into specific design schemes by combining specific products with restrictive conditions.

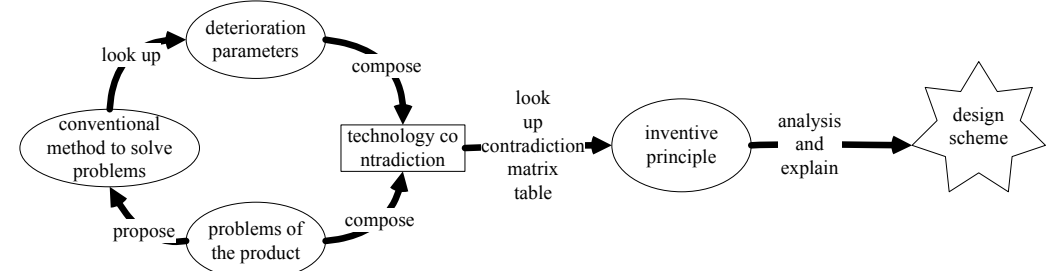

Fig. 3 The flowchart of using the contradiction matrix to solve the problems

Because the inventive principle we get from the contradiction matrix table is abstract, and it is difficult to apply directly, and the same invention principle for different product it will have different design schemes. So we should translate the invention principle to specific design scheme by combining specific products with restrictive conditions.

\section{Examples of applying contradiction matrix}

As the important component of fixture clamping, the design of clamping device, to some extent, determines the quality of the fixture. This paper use clamping device of milling fixture for instance to introduce how to use contradiction matrix in product innovation design. According definition of clamping device [6], clamping device of milling fixture is the tool that fixes workpiece after the workpiece is in its position, and makes it won't appear vibration or displacement when it suffer cutting force, inertia force and centrifugal force during machining, and ensure quality of the workpiece.

\subsection{Find the problems of clamping device by ideal final result.}

Though different types of machine tool fixture has different structure, but they generally compose by positioning device, clamping device, fixture body and other devices. The function of the clamping device of milling fixture is : clamping device makes workpiece won't appear vibration or displacement when it suffer cutting force, inertia force and centrifugal force during the process of machining. They compose mainly by device that provide power, force transmission mechanism and clamping element [6].

According to the function of clamping device, we want to get the IFR of clamping device is: workpiece can automatically be fixed without requiring additional components, and it will not generate vibration or displacement when it is processed. That is to say, workpiece can be fixed on milling fixture using no clamping device. But there is no such technology which has been used on milling fixture.

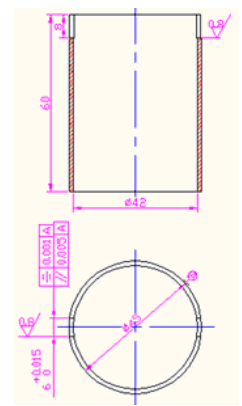

Fig. 4 Cylinder

This paper use the design of clamping device as an example which is used fixed cylinder on milling fixture. The size of the cylinder and the processing requirements are: outer circle diameter is $45 \mathrm{~mm}$, inner circle diameter is $42 \mathrm{~mm}$, in this paper we want to mill keyway which is $6_{0}^{+0.015} \mathrm{~mm}$ wide and $8 \mathrm{~mm}$ deep, and guarantee symmetry degree is $0.001 \mathrm{~mm}$ which both sides of the keyway to the axis of outer circle, and parallel degree is $0.005 \mathrm{~mm}$ which both sides of the keyway to the axis of outer circle. The specific requirements of the cylinder is shown in figure 4. 
In order to process large batch of cylinder described above, we should design special fixture to improve machining efficiency. At present, the typical design scheme of clamping device to machine cylinder keyway is shown in figure 5. According to the design scheme shown in figure 5, rotate eccentric came to the left, we can lose cylinder by the force of spring, and rotate eccentric came to the right, because eccentric cam and $\mathrm{v}$ block form self-locking, we can fix cylinder on the clamping device. We can see that this design scheme can realize to fix the cylinder quickly. But because the cylinder is thin, if the clamping force is great which providing by clamping device, the cylinder is easy to generate deformation; if the clamping force is small, the cylinder will produce obvious vibration and displacement when it is being machined.

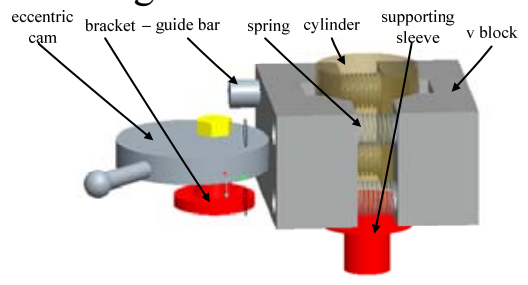

Fig. 5 Typical design scheme

When we design the clamping device, if we do not want the cylinder to produce vibration and displacement when it is being machined, the clamping device should offer greater force than the cylinder need to avoid it generate vibration and displacement. But at the force of clamping device, cylinder will generate deformation, which will reduce machining accuracy of the cylinder. Because of using clamping device, cylinder will have the problems mentioned above. Therefore, we can find the problems existing in the clamping device is: 1) generate deformation; 2) reduce machining accuracy. The flow chart given below help we find out the problems existing in the clamping device quickly. It is shown in figure 6.

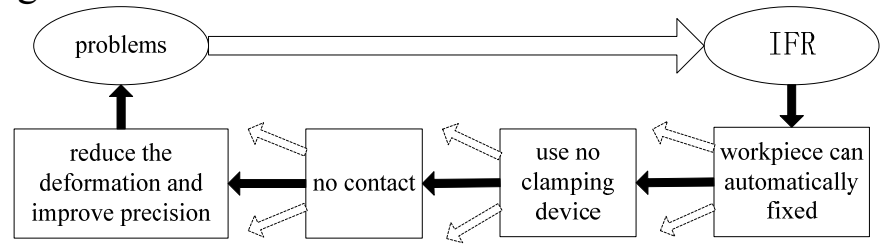

Fig. 6 The flow chart of using IFR to find problems of the clamping device

Because 39 engineering parameters of the contradiction matrix can describe most of problems in engineering field, and in order to apply contradiction matrix to solve the problems, we should convert these problems into corresponding engineering parameters. We can find out corresponding engineering parameters of the problems by comparing the problems with 39 engineering parameters of contradiction matrix. By comparison we can be sure that the parameters we want to improve in the clamping device is "shape" and "manufacturing precision".

\subsection{Be sure the invention principle of the technology contradictions.}

According to the method that using contradiction matrix to handle the technology contradictions, which is proposed above, we should firstly propose conventional method to try to solve the problems that existing in cylinder. In the face of these problems, this paper propose conventional method to solve them directly: Achieve the target by reducing the force of the clamping device. But reduce the force of clamping device will cause the cylinder occur vibration or displacement when it is being machined. Therefore, the problems that existing in the cylinder are one of the problems of two technical contradictions respectively. So we can use the contradiction matrix to solve them.

According to the conventional solution proposed above, if we reduce the force of clamping device, the cylinder will not be fixed on the clamping device. Comparing the problem to 39 engineering parameters, we can be sure the parameters is "force", which is cause by improving the "shape" and "manufacturing precision" of the cylinder. So, the technology contradictions of the cylinder are "shape" with "force" and "manufacturing precision" with "force". We can look up the contradiction matrix table [3] to find out invention principles to solve these technology contradictions. 
In order to show the problems existing in clamping device and to show the process which how we get the invention principles to solve these problems clearly, we make the steps above in a table, which is shown in the table 1.

Table 1 Find the invention principle by the problems of cylinder

\begin{tabular}{cccccc}
\hline Problems & $\begin{array}{c}\text { Engineering } \\
\text { parameter }\end{array}$ & $\begin{array}{c}\text { Conventional } \\
\text { solution }\end{array}$ & Deterioration problems & $\begin{array}{c}\text { Deterioration } \\
\text { parameters }\end{array}$ & $\begin{array}{c}\text { Invention } \\
\text { principle }\end{array}$ \\
\hline $\begin{array}{c}\text { Machining } \\
\text { accuracy is poor } \\
\text { Deformation }\end{array}$ & $\begin{array}{c}\text { Machining } \\
\text { accuracy } \\
\text { Shape }\end{array}$ & Reduce force & Vibration, displacement & Force & $28,19,34,36$ \\
\hline
\end{tabular}

Table 2 Translate the invention principle to design ideas

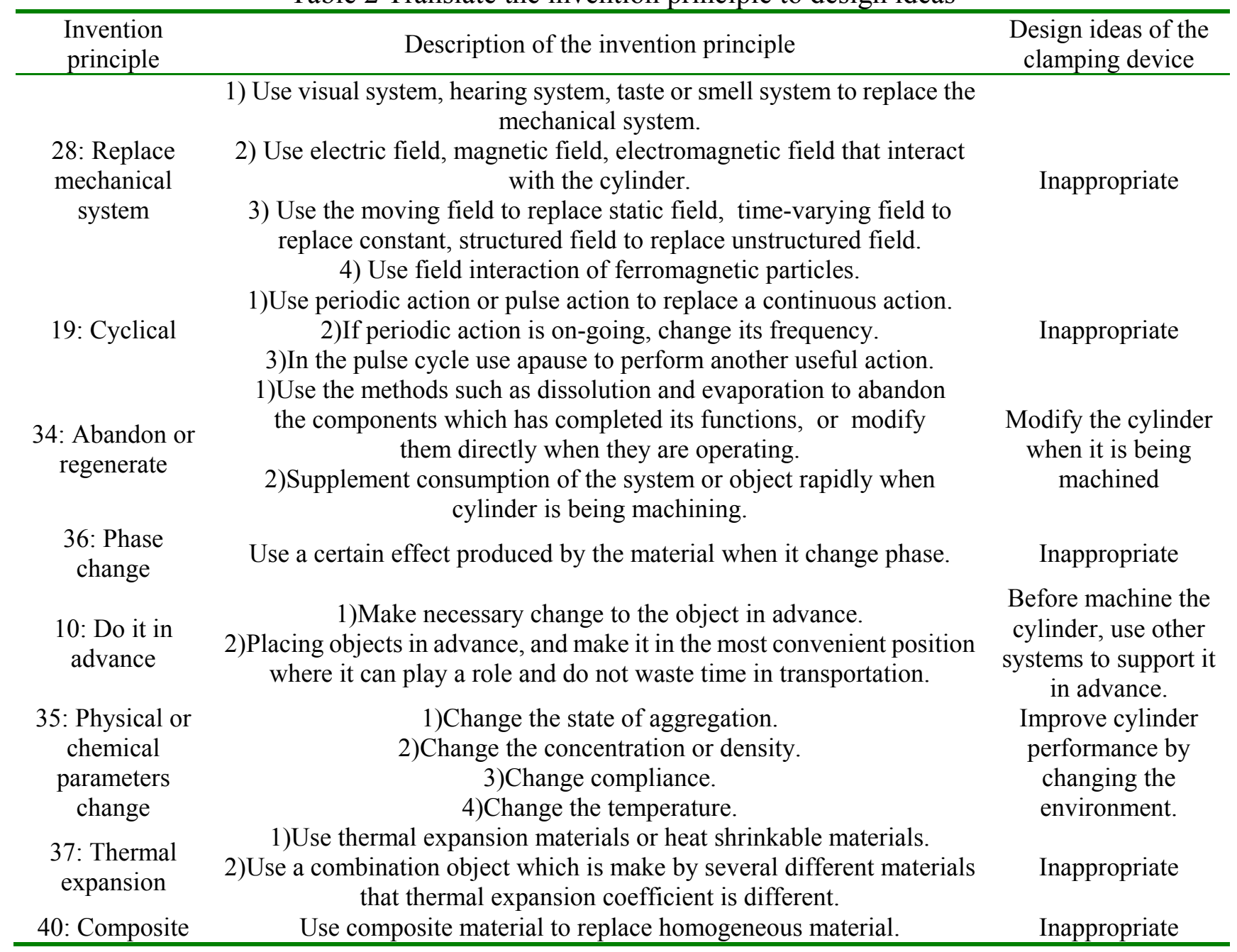

\subsection{Translate the invention principles into specific design schemes.}

Because the inventive principles we get from the contradiction matrix table is abstract, so we should translate the invention principles into specific design schemes by combining the restricted conditions of machining cylinder that provided in this paper with the invention principles we get above. We can get the design ideas of clamping device design, which is shown in table 2.

According to the design ideas of the clamping device in table 3, we can get design schemes which can reduce deformation and improve machining accuracy of the cylinder. The design schemes is shown in table 2.

Scheme 1: Modify the cylinder when it is being machined.

Because the machining precision of cylinder is reflected when it is machined. So if we can modify the deformation of cylinder in time, it will be effectual for processing accuracy, and will reduce the number of product scrap that is caused by excessive processing. Thus, we can measure the cylinder 
while it is being machined, and modify it according to the result of measurement. This method can realize the purpose of improving the machining accuracy of the cylinder.

Scheme 2: Before the cylinder be machined, using additional systems to support it in advance.

For the instance, we can insert cylinder that diameter is $42 \mathrm{~mm}$ into the workpiece before machine it, and which will improve machining accuracy of the workpiece in the end. This method can reduce deformation of the cylinder which is caused by the clamping device. The design scheme is shown in figure 7, which only show the part of clamping device that is changed.

Scheme 3: Improve cylinder performance by changing the environment.

Because the physical and mechanical properties of the metal materials are determined by the chemical composition of the material. So we can adjust chemical composition of the cylinder in reasonable range to improve the physical and mechanical properties [7].

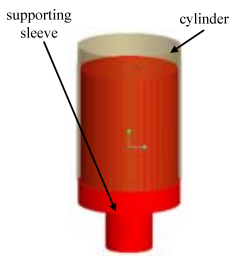

Fig. 7 Design scheme

Control the temperature when cylinder is being machined. According to the cylinder material, we can make the cylinder be machined in a suitable temperature, and make it has better processing performance. This can reduce deformation and improve machining accuracy [8].

In practical design, we may use two or more schemes to design the clamping device. Although these design schemes cannot achieve the IFR of the clamping device, they are more close to. So we can use these design schemes to design the clamping device.

\section{Summary}

Designers use traditional methods to find suitable scheme need to analysis lots of ideas they propose, eliminate many inappropriate ideas, and they might ignore part of schemes. Contradiction matrix can solve these problems very well, because it can focus on most likely design ideas which can solve the problems. In this paper, we can clearly reveal the convenience of using the contradiction matrix to solve problems by using it to design the clamping device of milling fixture.

\section{References}

[1]. Li T. Applying TRIZ and AHP to develop innovative design for automated assembly systems [J]. The International Journal of Advanced Manufacturing Technology, 2010, 46(1): 301-313.

[2]. Hsieh H T, Chen J L. Using TRIZ methods in friction stir welding design [J]. The International Journal of Advanced Manufacturing Technology, 2010, 46(9-12): 1085-1102.

[3]. Runhua Tan. TRIZ and Applications the Process and Methods of Technological Innovation [M]. Bei Jing: HIGHER EDUCATION PRESS, 2010, p. 393.

[4]. Shiyun Zhang, Yue Lin. Theory and Application of TRIZ [M]. Bei Jing: Cambridge University Press, 2010, p. 206-207.

[5]. Gadd K. Uncovering and Solving Contradictions [J]. TRIZ for Engineers: Enabling Inventive Problem Solving, 2011: 97-174.

[6]. Qing He, Yu Li. Milling fixture design tutoriall [M]. Bei Jing: PUBLISHING HOUSE OF ELECTRONICS INDUSTRY, 2012, p. 52-81.

[7]. Zhijing Feng. Mechanical manufacturing engineering principle [M], Bei Jing: TSINGHUA UNIVERSITY PRESS, 2011, p. 96-97.

[8]. Ge Liang, Huiying Shi. Mechanical engineering materials and heat treatment process [M], Bei Jing: CHINA MACHINE PRESS, 2006, p. 10-59. 